ción gigantesca; sólo porque nosotros no poseemos igual memoria y al leerlo nos perdemos con frecuencia en el dédalo, primero de sus frases, segundo de sus «côtés», creemos a primera vista en la obscuridad de sus períodos y en la falta de unidad de la obra. Mas la composición de ella está en proporción y perfectamente adaptada al vasto tema que trata. Sería ridículo exigirle que se angostara a las antiguas medidas de las obras unilaterales que en nada se le pueden comparar porque ésta es completamente original y, por consiguiente necesitó crear su forma adecuada (o, más bien dicho, su forma iba implícitamente contenida en el fondo, como debe suceder siempre que los autores tengan la sinceridad y la audacia de hacer las cosas como deben y no al revés).

A la recherche du temps perdu este título, genial «trouvaille», no es fantasista como parece en el primer momento; no ha sido inventado para «epatar» al burgués. Se le ha impuesto al autor mismo que (hay que hacerlo notar) tiene la modestia de considerar al artista como a un traductor; no como a una especie de improvisador. Este irreemplazable título viene, una vez más, a probarnos el espíritu de síntesis de su autor: es la coronación magnífica de esta obra única.-M A G D A E E NA PET I T.

\title{
La Doctrina de Monroe
}

TNTERROGADO sobre incidencias tan ruidosas como recientes, alguien formuló hace poco una definición inesperada:

- La Doctrina de Monroe es un enigma.

$\mathrm{Y}$ acaso traducen esas palabras una realidad.

Lo que maravilla cuando estudiamos el origen del célebre postulado, o cuando lo seguimos en sus evoluciones múltiples, es la impericia perseverante de que dieron prueba ante él los gobiernos de la América Latina. Ni comprendieron el significado, ni calcuilaron las consecuencias, ni vigilaron la aplicación. El árbol se alimentó con la savia de los que debían ser sus víctimas, y nadie indagó en beneficio de quién se desarrollaba, qué frutos debía dar, o hasta dónde alcanzaría su sombra.

Ciegos, sordos, mudos, los dirigentes dejaron que obrara la naturaleza, que en política suele tener abundancias de selva virgen. Sólo cuando las raíces levantaron los cimientos del propio suelo natal, parecieron empezar a darse cuenta de que algo ocurría. Pero ya era tarde. De aquí que nos encontremos a hora ante 
un conflicto que no depende de sutilezas protocolares o de argumentos leguleyos. Los Estados Unidos se han cuadrado ante el mundo y han dicho: no nos interesa lo que ustedes piensen, dentro o fuera de América; la doctrina existe porque la necesitamos; y su interpretación sólo depende de nosotros.

Por eso se puede decir que los expedientes a que recurren ciertos diplomáticos son inocuos.

Poco importa que la república $X$ declare que no se ha enterado aún del mensaje que Mr. James Monroe suscribió hacc. un siglo, o que la república $Z$ pida, sobre el alcance de dicha declaración, anacrónicos esclarecimientos a la Sociedad de las Naciones, que no existía en 1823 y de la cual no han formado nunca parte los Estados Unidos. Se necesita tener candor para suponer que estos juegos infantiles pueden ejercer alguna influencia sobre la marcha de los acontecimientos.

No se destruye el protectorado (la palabra fué empleada oficialmente por el Presidente Wilson en su discurso pronunciado el 9 de Enero de 1919, sin que ninguna de las repúblicas latino americanas levantase una protesta) dando un grito inútil y cobijándose de nuevo bajo el cálido regazo del supremo dispensador de empréstitos, o de Presidencias, que hace ley en el Continente. Eso servirá para contemporizar con la opinión pública; pero si se trata de rectificar realmente las direcciones de una política, si realmente se quiere salvar el porvenir, hay que reconocer que el procedimiento equivale a hostilizar a un elefante con un alfiler.

Nos hallamos en el nudo del drama, frente al enigma de que hablamos al comenzar. De nada valen las tímidas protestas que se traducen en declaraciones unilaterales, o en abstenciones aparatosas, a las cuales se quiere dar solemne significado. Al punto a que han llegado los acontecimientos, la Doctrina de Monroe no es ya una cuestión de diplomacia, sino de densidad. Empleamos la palabra en el sentido de masa y volumen. Nuestras Cancillerías, que no tienen visión de conjunto ni plan global, no hacen más que bordar arabescos verbales alrededor de una ley física que se hallan en la imposibilidad de torcer. Los Estados Unidos no las consultaron antes, ni las consultan ahora sobre si aceptan o no aceptan la tutoría. Sin cuidarse de lo que pensemos, la ejercen rotundamente. Y asíserá mientras duren los errores. En el estado actual de la América Latina, ninguna república se halla capacitada para impedirlo.

Pero la impotencia de los gobiernos actuales, la inutilidad de sus actividades tardías, tiene que ser el punto de arranque de la nueva política. Nada sería más torpe y más engañoso que 
entregarse al pesimismo y decretar que no queda nada que hacer. Miramos el tablero de ajedrez y comprendemos que podemos ganar aún la partida, a condición de jugar bien. Hay que afrontar el peligro con una conciencia solidaria. Sólo puede tener acción suficiente para detener o equilibrar la influencia que pesa sobre nosotros, un concierto de todas las repúblicas latino americanas realizado alrededor de un contra postulado defensivo. Es la obra de hombres nuevos en una América regenerada.

Tan bien hecho estaba el nudo que ataba la lanza al carro de Gordio, el viejo rey de Frigia, que nadie lograba descubrir los cabos. El oráculo había prometido el imperio a quien lo deshiciera. Pero era tan hábil el enredo, tenía tantas vueltas y revueltas, que no asomaba nunca principio ni fin. La Doctrina de Monroe, más que un enigma, es un nudo gordiano. En vano ensayan los políticos de nuestra América su ciencia y su paciencia. Siempre naufragan en insalvables dificultades. Pero esto no implica que el nudo no se pueda desatar. Yo no digo que imitemos el gesto de Alejandro. La diplomacia por renovadora que sea, tiene formas más suaves de expresión. Pero no cabe duda de que habrá que encararse con el obstáculo empleando sistemas adecuados a la magnitud del problema. No para conquistar, esta vez, el imperio, sino para detener su marcha.-M A N U E L U G A R T E.

距 Exclusivo para Atenea en Chile

\section{Sentido plástico de nuestra cultura}

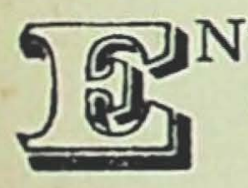

NTODOS los aspectos de la cultura y del progreso de nuestra época se advierte una pasión irreprimida por la forma y el color. Así es como el hombre contemporáneo busca la satisfacción de sus necesidades, cada vez más complejas, en la producción de una industria con apariencia artística. Ahí están el arte exclusivo y hechizado del letrero luminoso, el clarobscuro centelleante del cinematógrafo, la mística suntuosidad de las vidrieras comerciales, los caprichos estilizados de las indumentarias, las severas y flamantes creaciones de la ebanistería y el vasto prodigio del arte aplicado en general.

Margen habría para hacer un nutrido ensayo sobre la trascendencia social y psicológica de esta franca hiperestesia del sentido plástico. No otra cosa que la expresión de una libido 